\title{
A produção científica sobre avaliação educacional e gestão de sistemas e de escolas: o campo da questão entre 2000 e 2008
}

Angela Maria Martins*

Sandra Zákia Sousa**

\section{Resumo}

0 texto analisa produções acadêmicas que exploram possíveis relações entre gestão escolar e avaliação, com base em dissertações e teses, artigos de periódicos e anais da Associação Nacional de Pós-Graduação e Pesquisa em Educação (Anped) e da Associação Nacional de Política e Administração da Educação (Anpae), totalizando 25 documentos. 0 foco aqui aprofundado originou-se de Estado da Arte sobre gestão, autonomia e o funcionamento de órgãos colegiados em escolas públicas, que abrangeu o periodo entre os anos de 2000 a 2008 e reuniu 753 fontes documentais. A partir da identificação de eixos temáticos aglutinadores da produção em pauta, o texto busca explicitar contribuições teórico-metodológicas das pesquisas para compreensão da referida temática, bem como apontar eventuais subsídios para gestores de escolas e de redes. Verificou-se que, embora ainda incipiente, investigações que se dedicam a analisar as relações entre avaliações em larga escala e gestão escolar tendem a aumentar em curto espaço de tempo, tendo em vista a centralidade que o tema vem conquistando nas diretrizes políticas da área da educação.

Palavras-chave: Política educacional. Gestão escolar. Avaliação de larga escala.

\section{The scientific literature on educational assessment and management systems and schools: the field of matter between the years 2000 - 2008 Abstract}

The text examines academic productions that focus on possible relationships between school management and evaluation, based on dissertations and

\footnotetext{
* Pós-Doutorado em Políticas de Educação, Universidade de Lisboa; Pesquisadora da Fundação Carlos Chagas. E-mail: ange.martins@uol.com.br

** Doutora em Educação, Universidade de São Paulo (USP); Professora da Faculdade de Educação, USP. Email: zankia@usp.br
} 
theses, journal articles and proceedings from Associação Nacional de PósGraduação e Pesquisa em Educação (Anpae), in a total of 25 documents. The focus here deepened originated in the State of Acre on the management, autonomy and functioning of collegiate bodies in public school systems which covered the period between the years 2000 and 2008, and gathered 735 documental sources. From the identification of the agglutinated thematic axes in question, the text aims to clarify contributions to the theoreticalmethodological searches of that understanding, as well as to point out any possible subsidies for school managers and networks. It was found that, although still incipient, investigations that have dedicated themselves to analyze the relationship between large-scale assessment and school management tend to increase in a short period of time, in view of the prominence that the theme has been conquering in political guidelines in the field of education.

Keywords: Educational policy. School management. Large-Scale Assessment.

\section{La producción científica sobre evaluación educacional y gestión escolar $y$ de sistemas: su ámbito entre 2000 y 2008 Resumen}

El texto analiza producciones académicas que investigan posibles relaciones entre gestión escolar y evaluación, usa como base disertaciones y tesis, artículos de periódicos y anales de la Asociación de Posgrado e Investigación en Educación (Anped) y de la Asociación Nacional de Politica y Administración de la Educación (Anpae)-Brasil, lo que resulta un total de 25 documentos. El foco analizado se originó del Estado del Arte sobre gestión, autonomía y el funcionamiento de órganos colegiados en escuelas públicas, lo que abarcó el período entre los años 2000 a 2008 y reunió 753 fuentes documentales. A partir de la identificación de ejes temáticos aglutinadores de la producción en pauta, el texto busca explicitar contribuciones teórico-metodológicas de las investigaciones para la comprensión del tema, así como también señalar eventuales subsidios para gestores de escuelas y de redes. Se verificó que, aunque todavía incipiente, estudios que se dedican a analizar las relaciones entre evaluaciones de gran escala y gestión escolar tienden a aumentar en poco tiempo, teniendo en vista la centralidad que la temática viene conquistando en las directrices políticas del área de la educación.

Palabras clave: Política educacional. Gestión escolar. Evaluación de gran escala.

Este texto analisa produções que contribuem para explorar possiveis relações entre gestão e avaliação educacional, um dos focos identificados em estudos integrantes de Estado da Arte sobre gestão, autonomia e o funcionamento de órgãos 
colegiados em escolas públicas - que abrangeu o período entre os anos de 2000 a 2008 - organizado em banco de dados ${ }^{1}$.

A investigação original consistiu em levantamento de dissertações e teses coletadas no banco de teses da Coordenação de Aperfeiçoamento de Pessoal de Nível Superior (Capes), em artigos de periódicos e anais da Associação Nacional de PósGraduação e Pesquisa em Educação (Anped) e da Associação Nacional de Política e Administração da Educação (Anpae), fontes estas consideradas neste trabalho. Levantou-se um total de 753 documentos, sendo que 25 destes se dedicaram a explorar facetas da avaliação educacional e possíveis desdobramentos na gestão escolar. Tal constatação indica ser esta uma vertente ainda incipiente de pesquisas de estudiosos do campo da administração educacional, apesar da centralidade que a temática da avaliação vem conquistando nas diretrizes políticas da área.

O levantamento disponibilizado no banco de dados possibilita identificar uma pluralidade de temas e delineamentos assumidos nas produções, o que permite a realização de estudos com recortes analíticos específicos - caso deste trabalho - cuja motivação tem origem na identificação de uma tendência emergente, que trata da relação estabelecida entre resultados mensuráveis e/ou dados observáveis - em especial resultados de desempenho de alunos e escolas nas avaliações de larga escala - e questões relacionadas à gestão escolar e de redes. Embora ainda sejam escassos, estudos dessa natureza trazem uma discussão fundamental em torno do tema da gestão no tocante a mecanismos que subsidiem perspectivas de melhoria da qualidade do ensino ofertado. Há ainda investigações que exploram abordagens complementares às avaliações de desempenho de aluno, focalizando a avaliação institucional.

Temos clareza de que as fontes consultadas para composição do banco de dados não abarcam, de modo exaustivo, as publicações que acolhem textos relativos à temática da avaliação educacional, pois o levantamento original se pautou pelos temas da gestão, da autonomia e de órgãos colegiados, buscando observar não apenas o que os autores apontavam nos resumos, títulos e palavras-chave como objeto de pesquisa, mas também os conceitos e categorias de análise presentes no desenvolvimento dos textos. Nesse movimento, as questões que envolvem a discussão sobre avaliação apareceram de forma tangencial, configurando uma produção que se torna gradualmente presente no debate sobre gestão, sobretudo a partir de 2005.

\section{Os estudos em foco}

Visando a elucidar concepções que fundamentam os estudos e suas potencialidades para trazer subsídios ao debate acerca de relações entre gestão e avaliação,

\footnotetext{
O Estado da Arte: gestão, autonomia da escola pública e órgãos colegiados (2000-2008), foi financiado pela Fapesp e coordenado por Ângela Maria Martins (2010). 0 banco de dados está disponível no site da Fundação Carlos Chagas.
} 
elegeram-se algumas questões a serem exploradas nesta análise: As pesquisas podem ser agrupadas em torno de quais eixos? Que contribuições teórico-metodológicas os estudos trazem para o avanço do conhecimento no que diz respeito a aportes que a avaliação possa trazer para a gestão educacional? Os estudos se preocupam em reunir subsídios para gestores de redes e de escolas?

0 acesso ao Banco de Dados permitiu a identificação de 12 artigos, duas teses de Doutorado, seis Dissertações de Mestrado e cinco textos publicados em Anais da Anped e da Anpae, referenciados bibliograficamente, que abordam a questão, com diferentes niveis de aproximação. Estes textos foram agrupados em quatro eixos, tendo em conta o recorte temático, quais sejam:

1) efeito escola e/ou características de escolas eficazes - seis estudos;

2) características de resultados de avaliação de desempenho de alunos e perfis de diretores e de modelos de gestão - quatro estudos;

3) avaliação institucional - 12 estudos;

4) usos dos resultados de avaliação de desempenho para implementação de políticas educacionais e processos de gestão - três estudos.

Seguem-se resumos dos textos, agrupados por eixo, seguidos de considerações que exploram eventuais contribuições para o debate acadêmico nesse campo e possiveis aportes para gestores de redes e escolas.

\section{Primeiro Eixo: efeito escola e/ou características de escolas eficazes}

Estão agrupados no Quadro 1, seis estudos - quatro artigos, uma dissertação de mestrado e um trabalho publicado em Anais da Anped - que buscam associar avaliação de desempenho e o papel da escola, voltados a explorar efeito escola e/ou características de escolas eficazes, adotando esta perspectiva e/ou alertando para seus limites.

Quadro 1: Estudos que associam avaliação de desempenho de alunos e o papel da escola.

\begin{tabular}{|l|c|c|}
\hline Autor (es) & Tipo de Fonte & Ano \\
\hline BRANDÃO & Artigo & 2000 \\
\hline MACHADO & Dissertação & 2003 \\
\hline RIBEIRO & Anais da Anped & 2004 \\
\hline SOARES e ANDRADE & Artigo & 2006 \\
\hline FONSECA & Artigo & 2007 \\
\hline SOARES e CANDIAN & Artigo & 2007 \\
\hline
\end{tabular}

Fonte: As autoras (2011). 
Fonseca (2007) sumariza contribuições elaboradas por outros pesquisadores que buscaram elucidar fatores de "escolas eficazes"2. Não se trata de estudo empírico, de ensaio ou de estudo com características mais argumentativas: é apresentação sucinta de uma obra - referência no Brasil por trazer tradução das principais investigações realizadas em âmbito internacional, além de registrar pesquisas desenvolvidas em território nacional - assinalando os principais pontos abordados em suas diferentes partes.

Soares e Andrade (2006), associando-se aos estudos que discutem o efeito de escolas no desempenho cognitivo dos alunos, apresentam resultados de pesquisa que abrangeu unidades públicas e particulares do município de Belo Horizonte. Tomando como referência dados do Sistema Mineiro de Avaliação Educacional (Simave) do ano de 2002 e dos vestibulares da Universidade Federal de Minas Gerais de 2002 a 2004, os autores, recorrendo a técnicas estatísticas, produziram medidas do nivel socioeconômico das escolas, de sua qualidade acadêmica (desempenho cognitivo dos alunos), além de analisarem os resultados das avaliações sob a perspectiva da equidade da escola.

Soares e Candian (2007) exploram, tal como na pesquisa anteriormente mencionada, o efeito de escolas de Educação Básica do país, públicas e particulares, no desempenho dos alunos, apoiando-se em dados do Sistema de Avaliação da Educação Básica (Saeb) e do Programme for International Student Assessment (Pisa). Embora reconhecendo as limitações dos dados tomados como referência para o estudo em pauta, os autores afirmam serem esses os melhores instrumentos disponiveis para analisar efeitos de fatores referentes à gestão e à infra-estrutura escolar e pedagógica sobre a qualidade e equidade.

A relação entre gestão e qualidade escolar é analisada por Machado (2003), que toma como pressuposto duas categorias: a eficácia e a efetividade. A autora assume que a noção de eficácia escolar está diretamente relacionada à qualidade, e a efetividade à gestão democrática. Com base em pesquisa realizada em duas escolas públicas da rede estadual de Minas Gerais, o trabalho indica que a avaliação sistêmica, ao atingir os alunos da $4^{\mathrm{a}} \mathrm{e}$ da $8^{\mathrm{a}}$ séries do Ensino Fundamental, mede apenas a qualidade acadêmica de alguns, sendo que a maioria permanece retida no fluxo escolar, em decorrência da repetência e da evasão.

Ribeiro (2004) apresenta dados coletados em escola pública, escolhida com base na análise de resultados de desempenho dos alunos no exame denominado Sistema de Avaliação de Rendimento Escolar do estado de São Paulo (Saresp), em 1998. Tomando por referência a literatura do campo que relaciona sucesso escolar e escolas eficazes, a autora busca identificar os elementos de contexto - contidos no instrumento aplicado pela Secretaria de Estado da Educação de São Paulo - que impactam o sucesso na gestão escolar: autonomia, clima, presença de liderança, ênfase no ensino-aprendizagem e desenvolvimento profissional dos professores.

2 A referência central do autor é o livro "Pesquisa em eficácia escolar: origem e trajetórias", compêndio organizado por Brooke e Soares (2008) e que traduz estudos realizados em diversos países que expressam momentos da história dessa linha de pesquisa. 
Em abordagem que se diferencia dos demais artigos mencionados, Zaia Brandão (2000) - a partir de considerações sobre a seletividade dos sistemas escolares e de fatores intra e extraescolares que condicionam o processo de escolarização - problematiza dificuldades teóricas e metodológicas relativas às pesquisas sobre efetividade escolar. Apoiando-se em duas revisões de pesquisas - sobre efeito escola realizada por Pascal Bressoux (1994) e sobre a efetividade das escolas realizada por Coe e FitzGibbon (1998) ${ }^{3}$ - a autora destaca evidências para analisar os contextos - diversos e heterogêneos - em que são apreendidos os indicadores de efetividade escolar. Menciona os principais problemas e desafios a serem enfrentados por pesquisadores que se dedicam ao estudo sobre efetividade das escolas: os limites do uso de resultados de testes cognitivos como referência central de efetividade escolar e a fragilidade dos modelos estatísticos usados para o cálculo do valor agregado bem como das conexões causais estabelecidas entre escolas e efetividade. Há, ainda, referência a que se atente para a não comparabilidade de conclusões de diferentes estudos, pois as características de escolas efetivas podem, sob um mesmo termo, expressar concepções diversas e/ou divergentes delineadas em cada pesquisa. Por fim, alerta para as consequências negativas do uso indiscriminado de resultados de testes.

Observando o conjunto dos trabalhos deste primeiro eixo, nota-se que dos seis trabalhos captados no estudo original, apenas três fazem uso de dados estatísticos de avaliações de larga escala com a intenção de aquilatar variáveis que incidem sobre o ensino e/ou desempenho dos alunos. Há que se registrar que, no Brasil, os estudos sobre efeito escola são recentes e vêm sendo desenvolvidos por poucos grupos de pesquisadores que detêm domínio de metodologias e técnicas de geração e tratamento estatístico de dados. Um quarto trabalho lança mão de dados resultantes de avaliação sistêmica implementada no estado de Minas Gerais, para aprofundar a discussão sobre esses resultados em estudo de caso realizado em duas escolas. Um dos trabalhos, ainda, tem delineamento argumentativo, o que contribui sobremaneira para o aprofundamento do debate sobre as avaliações de larga escala e seus desdobramentos efetivos em escolas, e outro se restringe a sumariar uma obra específica.

\section{Segundo eixo: avaliação de desempenho de alunos e modelos de gestão}

No Quadro 2, estão reunidos quatro estudos - uma dissertação de mestrado, dois artigos e uma tese de doutoramento - que buscam associar características de resultados de avaliação de desempenho de alunos com perfis de diretores e com modelos de gestão.

3 Brandão (2000) lança mão de revisões sobre estudos de efetividade das escolas, que apontam tensões, possibilidades e limites de investigações dessa natureza e iluminam oportunas questões de pesquisa. Ver Bressoux (1994) e Coe e Fitz-Gibbon (1998). 
Quadro 2: Estudos que associam resultados de avaliação de desempenho de alunos e modelos de gestão.

\begin{tabular}{|l|c|c|}
\hline Autor (es) & Tipo de Fonte & Ano \\
\hline GOMES & Dissertação & 2004 \\
\hline SOARES e TEIXEIRA & Artigo & 2006 \\
\hline SOUZA & Tese & $2007 \mathrm{a}$ \\
\hline SOUZA & Artigo & $2007 \mathrm{~b}$ \\
\hline
\end{tabular}

Fonte: As autoras (2011).

Soares e Teixeira (2006) definem como uma das vertentes do trabalho a caracterização de práticas de diretores, classificadas em conservadora, democrática e gerencial. Tais práticas foram relacionadas ao desempenho de alunos em provas de Língua Portuguesa, integrantes dos instrumentos do Sistema Mineiro de Avaliação (Simave). Os pesquisadores identificaram a presença, ou não, de associação estatística entre diretores democráticos, gerenciais e conservadores e o desempenho dos alunos em Língua Portuguesa, por meio de modelos hierárquicos de regressão. Concluem que nas escolas nas quais atuam diretores classificados como "amplamente democráticos", embora sendo um número reduzido, os alunos apresentaram alta proficiência em Língua Portuguesa.

Souza (2007b), em artigo publicado - resultado de sua tese de doutoramento (2007a) -, relaciona desempenho estudantil e gestão e direção de escola em abordagem que denomina efeito-gestão ou efeito-direção escolar. Coteja a experiência e qualificação profissional de diretores e proficiência estudantil em Língua Portuguesa e Matemática, utilizando dados do Saeb de 2003. Os resultados obtidos com o estudo sugerem que características dos diretores e a democratização da gestão são fatores que incidem sobre resultados obtidos pelas escolas. Os efeitos de mudanças preconizadas pelas reformas da educação na gestão escolar são analisados por Gomes (2004), com vistas a discutir de que forma estas enfocam o papel dos diretores de escola. 0 trabalho caracteriza o perfil de diretores da escola fundamental e estilos de gestão escolar existentes no Brasil e no Estado do Rio de Janeiro, com base em dados apresentados pelo Saeb 2001.

0 delineamento assumido em dois dos estudos aqui registrados visa a aquilatar relações entre estilos de gestão e desempenho de alunos, tendo em comum a afirmação favorável a princípios democráticos de gestão. A partir de estudos dessa natureza, é difícil afirmar suas possiveis contribuições para o avanço de conhecimento na área ou mesmo para subsidiar a gestão de redes e escolas, considerando-se que estilo de gestão não é algo que possa ser prescrito, partindo-se de resultados de desempenho de alunos e relacionando ambas as dimensões de forma causal. Em realidade, a gestão democrática pode ser analisada tomando por pressuposto valores e concepções de indivíduos e grupos representativos da sociedade civil - dentre os quais se incluem os diferentes segmentos profissionais que atuam no espaço escolar - portanto, sua qualificação extrapo- 
la quaisquer relações estabelecidas linearmente entre resultados de avaliações em larga escala e perfis de atuação de diretores escolares. Ainda que pesquisadores lancem mão de constructo teórico como ponto de partida de trabalhos empíricos - por exemplo, como no caso do modelo clássico de perfil de direção democrático, conservador e burocrático -, é fundamental que, ao final desse percurso, a análise incorpore os dados de modo a que, efetivamente, extrapole o modelo teórico adotado.

\section{Terceiro eixo: avaliação e autoavaliação institucional}

Neste eixo estão reunidos doze estudos - quatro trabalhos publicados em anais de simpósios da Anpae, quatro dissertações de mestrado, uma tese de doutoramento e três artigos que se dedicam a examinar processos de avaliação institucional.

Quadro 3: Estudos que tratam de avaliação institucional.

\begin{tabular}{|l|c|c|}
\hline Autor (es) & Tipo de Fonte & Ano \\
\hline MAIA & Anais da Anpae & 2001 \\
\hline SOUILASSE & Dissertação & 2001 \\
\hline COELHO & Artigo & 2002 \\
\hline OLIVEIRA & Dissertação & 2002 \\
\hline FREITAS & Artigo & 2005 \\
\hline MAZZIEIRO & Artigo & 2006 \\
\hline BRANDALISE & Anais da Anpae & 2007 \\
\hline GROCHOSKA e EYNG & Anais da Anpae & 2007 \\
\hline MORAES E SILVA & Anais da Anpae & 2007 \\
\hline MORAES & Dissertação & 2008 \\
\hline SILVA & Tese & 2008 \\
\hline DALBEN & Dissertação & 2008 \\
\hline
\end{tabular}

Fonte: As autoras (2011).

Ao examinar o conceito de qualidade negociada e discutir as potencialidades da avaliação institucional, Freitas (2005) tem como alvo apresentar subsídios que promovam maiores compromissos de servidores e gestores públicos com políticas democráticas. 0 autor realça a importância de se mobilizar as escolas por meio de processos de avaliação institucional participativos. Sublinha a importância da construção de um processo de acompanhamento longitudinal do desempenho de estudantes, em conjunto com a avaliação institucional.

Apoiado nos campos teóricos das áreas de gestão educacional, avaliação institucional e informática aplicada à gestão educacional, Mazzieiro (2006) apresenta um software de suporte à coleta eletrônica de dados voltado à avaliação institucional de unidades escolares de educação básica e instituições de ensino superior. 0 autor 
conclui que nas instituições nas quais foram realizadas as aplicações experimentais do software se realizou a meta-avaliação do aplicativo, possibilitando a introdução de melhorias institucionais.

Maia (2001) descreve a implantação da avaliação institucional na rede estadual de escolas do Ceará e seus aspectos metodológicos, com ênfase na gestão escolar e na organização do trabalho docente. A pesquisa-ação realizada por Grochoska e Eyng (2007) foi implementada com base em questionários e grupos de discussão. As autoras abordam as politicas de avaliação institucional nas escolas de Educação Básica, em busca de instaurar a melhoria das instituições de ensino, em defesa de uma experiência de gestão democrática levada a efeito no estudo. Nessa perspectiva, analisam as possibilidades da autoavaliação institucional para a ampliação dos mecanismos democráticos de gestão de escola da Educação Básica.

0 estudo de caso desenvolvido por Brandalise (2007) - implementado com base em grupo focal realizado com professores, funcionários e pais de uma escola localizada em município do Paraná -, apresenta o processo de construção de uma proposta de autoavaliação para Escola Básica, que procurou sistematizar e disponibilizar aos profissionais envolvidos, conceitos, procedimentos e instrumentos de desenvolvimento institucional.

A implementação de autoavaliação institucional em escola pública de pequeno porte e de zona rural, da rede estadual de São Paulo é examinada por Moraes (2008) que chama a atenção para a importância desse recurso face à necessidade de se ampliar os mecanismos de gestão democrática e de se estabelecer uma cultura avaliativa que se distancie do mérito ou da punição, subsidiando práticas de transformação nas escolas. Moraes e Silva (2007) discutem resultados de pesquisa qualitativa realizada com base em análise de documentos oficiais orientadores do Progestão-SP e do Prêmio Nacional de Referência em Gestão Escolar, bem como em dados obtidos em estudo de caso. A pesquisa analisa a prática de coordenação pedagógica em escola pública estadual de São Paulo, que promoveu e coordenou durante dois anos, um processo de autoavaliação institucional, apoiada pela direção da unidade escolar.

O Sistema Permanente de Avaliação Educacional do Estado do Ceará (Spaece) é analisado por Coelho (2002), apontando que sua composição se estrutura em dois eixos substanciais para a formulação das políticas educacionais e pela prestação de contas à sociedade: a Avaliação do Rendimento Escolar e a Avaliação Institucional.

0 mesmo tema - avaliação institucional - é examinado por Silva (2008), com foco nas políticas de reforma do ensino técnico implementadas após a Lei de Diretrizes e Bases da Educação Nacional (BRASIL, 1996), tomando por base o Sistema 
de Avaliação Institucional das Escolas Técnicas Estaduais (SAI-ETEs) do Centro Paula Souza no Estado de São Paulo (1997-2007). A autora evidencia que o principal eixo da discussão sobre qualidade do ensino baseia-se no tripé avaliação-qualidade-autonomia, como instrumento de regulação do financiamento público.

A avaliação tem se resumido a aspectos de rendimento escolar do aluno e raras vezes são abordadas dimensões mais abrangentes da escola que possam contribuir para o aprimoramento do ensino público, na visão de Squilasse (2008). A autora conclui que na pauta da área aparecem como eixos centrais a participação ativa e a decisão colegiada; entretanto, os procedimentos de avaliação institucional nas escolas públicas não possibilitam que as decisões tomadas sejam compatíveis com as necessidades, possibilidades e limites da escola.

Tomando por base literatura disponível da área, Oliveira (2002) examina a avaliação no contexto da organização do trabalho pedagógico de uma escola pública do Distrito Federal, em busca de articulá-la com a elaboração do projeto político-pedagógico. A autora conclui que há uma prevalência da avaliação centrada no desempenho do aluno, de forma unilateral, chamando a atenção para o fato de que seus usos não revertem em subsídios para a reorganização do trabalho pedagógico.

Aspectos que influenciam a implantação da Avaliação Institucional Participativa foram examinados por Dalben (2008) que, ao investigar uma escola estadual do Ensino Fundamental, salienta que este recurso amplia as possibilidades de gestão democrática e favorece a articulação entre o serviço público e seus usuários, o que contribui para a melhoria da qualidade educacional.

Note-se que neste eixo são encontradas doze fontes documentais, abarcando o maior número de trabalhos. Esse interesse parece ser crescente e pode ser expressão de crença dos pesquisadores que essa perspectiva se constitui em instrumento que permite refletir sobre a realidade escolar, ampliando as dimensões avaliativas nas escolas e seus efeitos na qualidade da educação. Acrescente-se que a própria noção de qualidade pode ser repensada face às contribuições trazidas por práticas institucionais de avaliação, que possibilitem redirecionamentos na implementação das atividades pedagógicas e administrativas, articuladas por todos os atores envolvidos nesses processos.

Dessa forma, os pesquisadores chamam a atenção para o fato de que as avaliações institucionais - para além de diagnosticar problemas nas escolas e nas relações que nesse espaço se estabelecem - retiram das avaliações de larga escala o peso que estas vêm assumindo no que diz respeito a se constituir na referência quase que exclusiva de padrão de qualidade da educação ofertada pelo setor público. 


\section{Quarto eixo - Avaliação de Desempenho e Gestão de Sistemas de Ensino}

A utilização de resultados de avaliação de desempenho para analisar políticas implementadas e iniciativas de gestão de sistemas de ensino foi a perspectiva assumida em três dos trabalhos aqui analisados, publicados como artigos em periódicos.

Quadro 4: Estudos que tratam da utilização de resultados de avaliação de desempenho para gestão de sistemas de ensino.

\begin{tabular}{|l|c|c|}
\hline Autor (es) & Tipo de Fonte & Ano \\
\hline FREITAS & Artigo & 2006 \\
\hline VIEIRA & Artigo & 2007 \\
\hline ALVES & Artigo & 2008 \\
\hline
\end{tabular}

Fonte: As autoras (2011).

Freitas (2006) trata do desaproveitamento escolar, mencionando diretrizes e estratégias da União voltadas para a promoção da qualidade do ensino, a partir dos anos 1990 com destaque para a criação do Sistema de Avaliação da Educação Básica (Saeb) e a modernização dos procedimentos de geração e disseminação de informações educacionais, além de disposições normativas. A partir desse cenário, focaliza iniciativas desencadeadas no estado de Mato Grosso do Sul e no município de Dourados, no período 1993-2004. Tendo como referência taxas de reprovação escolar e resultados do Saeb, constata que o desaproveitamento escolar é expressivo no estado em pauta. Dentre as estratégias implementadas no estado para enfrentar os problemas de fluxo e qualidade do ensino, é dado realce à avaliação. Uma evidência nessa direção é a criação de um sistema estadual de avaliação, denominado Sistema de Avaliação da Educação Básica de Mato Grosso do Sul (Saems). No que se refere ao município de Dourados, a autora registra iniciativas do período considerado, as quais, no entanto, não foram duradouras em decorrência da alternância de poder na gestão educacional, com gestores de perfil e compromissos diversificados. Trazendo resultado de estudo realizado em algumas escolas estaduais e municipais, em 2004, comenta que tanto a regulação normativa quanto o monitoramento da qualidade do ensino não têm induzido a empenho na gestão do desaproveitamento escolar.

A relação entre rendimento de alunos, redes de ensino e anos, em que a avaliação foi realizada, constitui estudo implementado por Alves (2008), com base em modelos multiníveis de classificação cruzada: alunos dentro de redes e redes dentro de anos de aplicação do Saeb. A autora - esclarecendo que considera políticas educacionais de forma tópica - conclui que as que estão associadas ao aumento do desempenho de alunos das capitais brasileiras se devem aos seguintes fatores: escolha meritocrática e democrática de diretores, autonomia financeira, implementação de sistemas de avaliação, oferta e cobertura na educação infantil e formação superior de docentes das redes. 
Vieira (2007) analisa politicas educacionais implementadas no estado do Ceará entre 1995 e 2002 e 2003/2006, tomando como questão central a sua continuidade/ descontinuidade. Assinala a importância que os sistemas de avaliação vêm adquirindo na gestão educacional e aponta que o desempenho escolar é tido como um dos principais indicadores do sucesso das políticas educacionais. Discute a estruturação do Sistema Permanente de Avaliação da Educação Básica no estado de Ceará (Spaece), a partir de 1992, chamando a atenção para os diferentes tipos de relatórios gerados para a divulgação dos resultados para toda a rede. Esse processo subsidiou, dentre outras medidas, a estruturação do Programa Gestão por Resultados - monitorado pelo Instituto de Pesquisa e Estratégia Econômica do Ceará (Ipece) - e do Sistema de Inclusão Social (SIS), conjunto de metas estabelecidas para todas as áreas de Governo.

Embora na pesquisa que deu origem ao Banco de Dados tenham sido localizados apenas três estudos a respeito do uso de resultados de avaliação e sua relação com políticas educacionais, há que se reconhecer que essa é uma temática que vem conquistando visibilidade nos últimos anos.

Os textos reunidos neste quarto eixo trazem, a partir de suas especificidades, elementos que colaboram com esse debate. Dentre as contribuições presentes, são aqui exploradas aquelas que se tratam mais diretamente da articulação entre resultados de avaliação e formulação e gestão de políticas educacionais, reconhecendo a especificidade dos recortes analíticos assumidos pelas autoras.

Enquanto Alves (2008) divulga análise de fatores explicativos da variação de desempenho de alunos em avaliações de larga escala e delineia intervenções que se mostram potencialmente capazes de incidir positivamente nos resultados, alertando para a necessidade de que gestores debatam os resultados alcançados pelas escolas sem preconceito, Freitas (2006) e Vieira (2007) relatam e analisam iniciativas desencadeadas no âmbito da gestão de sistemas de ensino, elucidando a articulação entre resultados de avaliações e a implementação de políticas educacionais em contextos específicos, em períodos recentes, delimitados temporalmente.

Freitas (2006), tendo como referência ações desencadeadas no estado de Mato Grosso do Sul e no município de Dourados, no periodo 1993-2004, embora reconheça na avaliação a estratégia escolhida para indução de melhoria da qualidade do ensino, traz evidências de seu fraco poder indutor, indicando que seus resultados vinham gerando, à época, pouco empenho dos gestores no enfrentamento do fraco rendimento escolar.

No caso das políticas educacionais implementadas no Estado do Ceará, entre os anos 1995 e 2006, o que se evidencia é a importância adquirida pelos sistemas de avaliação na condução das políticas educacionais, sendo seus resultados tomados como indicadores de efeitos das políticas implementadas, além de prover aportes para a gestão do sistema educacional. 


\section{Considerações finais}

No escopo dos vinte e cinco trabalhos aqui analisados, quatro deles - agrupados no primeiro eixo -, tomam como referência dados de avaliações de larga escala - implementadas pela esfera federal ou por governos estaduais - para realizar pesquisas baseadas em diferentes modelos estatísticos tais como o de regressão e de multiníveis de classificação cruzada, apenas para citar alguns. Abordam fatores de efetividade das escolas, ou seja, aqueles que podem incidir positivamente ou não no rendimento dos alunos e alertam para a relevância de pesquisas empíricas, ressaltando seu potencial de subsidiar iniciativas que se voltem à melhoria da qualidade da educação brasileira. $\mathrm{Na}$ ótica em que este primeiro agrupamento de trabalhos foi apreciado - considerando suas contribuições para trazer subsídios ao debate acerca de relações entre gestão e avaliação - o que se nota é que estes não focalizam diretamente a gestão escolar, mas consideram diversos elementos de contexto que têm efeitos na qualidade do ensino, induzindo, mesmo que indiretamente, a que se pensem alternativas de gestão pedagógica e administrativa capazes de promover a melhoria do ensino no âmbito da escola.

É preciso assinalar ainda que, no primeiro eixo, se encontra um artigo argumentativo (BRANDÃO, 2000), que consubstancia críticas ao discutir limitações e riscos de se estabelecer relações lineares entre determinadas variáveis e resultados escolares para se pensar a efetividade escolar, sublinhando a complexidade e especificidade dos diferentes contextos. Considerando os alertas trazidos por este trabalho, a apropriação de resultados de pesquisas sobre eficácia escolar por gestores merece ser feita com precaução, evitando-se tomar como regra de sucesso variáveis que se mostraram pertinentes a dada realidade, num determinado tempo e espaço e a partir de uma dada concepção de qualidade. A autora observa, ainda, a necessidade de se atentar para a tendência de consagração de metodologias sofisticadas, que podem servir menos aos atores dos sistemas (professores, diretores, coordenadores, secretários) e mais ao interesse acadêmico.

Ao se indagar as contribuições teórico-metodológicas das pesquisas sobre efetividade escolar para a gestão educacional, evidencia-se, por um lado, a importância de se adensarem estudos que busquem analisar variáveis que incidem positivamente no trabalho e nos resultados escolares. Por outro lado, também cabem investigações interessadas em responder a questionamentos que surgem com insistência nesse campo e que assinalam, entre outros aspectos, a consistência e as contradições de resultados de pesquisas sobre a efetividade da escola, atribuidos a fatores identificados apenas em seu interior.

Nos trabalhos agrupados no segundo eixo, todos os quatro lançam mão de dados estatísticos buscando estabelecer relações entre desempenho de alunos, perfil e modelos de gestão escolar. Entretanto, o delineamento assumido nessas pesquisas, ao tempo em que permitem aquilatar fatores que influenciam as trajetórias 
de escolarização de alunos, articulando-os à gestão da escola e/ou ao perfil de diretores, podem limitar a própria concepção de gestão e de sua qualidade à proficiência de alunos em avaliações em larga escala, desvelando uma visão linear.

Dos estudos que tomam como foco a avaliação ou autoavaliação institucional agrupados no terceiro eixo - dois deles se voltam à análise de experiências próprias dos autores, implementadas em instituições de ensino.

Nota-se que apenas um estudo foi realizado por meio de pesquisa-ação, uma das abordagens qualitativas que tem potencial para concretizar a articulação entre o conhecimento produzido no âmbito acadêmico e as redes de ensino e escolas. Tratando-se de avaliação institucional, que remete ao envolvimento e participação de diferentes atores escolares, esta é uma perspectiva que, bem conduzida, pode suscitar novos elementos para consolidar a escola como sujeito da avaliação.

Os demais textos argumentam de que forma a avaliação institucional pode subsidiar processos decisórios de estabelecimentos, promovendo mudanças no perfil da gestão escolar em moldes democráticos. Alguns realizam estudos de caso - enfocando o papel do coordenador pedagógico, o processo de elaboração do projeto políticopedagógico e a ampliação de mecanismos de participação em avaliação institucional em escola pública -, enquanto outros tomam como horizonte a análise do conjunto legal e normativo que regulamenta as medidas avaliativas em âmbito federal ou em unidades federadas, caso de São Paulo, Paraná, Minas Gerais e Ceará.

No quarto eixo, encontram-se dois trabalhos que lançam mão de dados estatísticos e análise documental para analisar a dimensão política da avaliação, assinalando que a efetivação do direito à educação pode tomar a avaliação como ferramenta de gestão, mas que é preciso pensar, porém, que as políticas educacionais têm contribuido de forma modesta para o aumento no desempenho de alunos, sem a dimensão necessária ainda para que o país enfrente os desafios de uma escolarização equânime e de qualidade. Um dos trabalhos ressalta a necessidade de que gestores e pesquisadores debatam os resultados alcançados pelas escolas sem preconceito, incluindo na pauta das discussões temas tais como ampliação da autonomia e currículos melhor estruturados. Nesse agrupamento de textos, apenas um apresenta aspecto argumentativo ao analisar a implementação de políticas educacionais com base no escopo de medidas e programas estruturados pela esfera estadual ao longo de um período de tempo.

A produção científica aqui examinada traz pistas para o delineamento teóricometodológico de outros estudos que, porventura, pretendam explorar aportes que a avaliação possa trazer para a gestão educacional, bem como suscitam indagações e apontam algumas perspectivas a gestores de redes e de escolas. Entretanto, esta- 
belecer relações entre rendimento de alunos e gestão escolar que se pretenda "democrática e ou participativa" - como pressupõem muitos dos estudos captados no banco de dados da investigação original referenciada no início deste trabalho exige cuidados redobrados. A polissemia do termo "gestão democrática" pode levar boa parte dos estudiosos a confundir o "tema" com o próprio "objeto de pesquisa", tendo em vista que a constatação de "uma boa gestão escolar" não pode estar fundamentada - linearmente - em sua relação com o desempenho de alunos. Outros elementos compõem as dinâmicas escolares cujas equipes de gestão logram sucesso na qualidade do ensino ofertado e em seus resultados (MARTINS, 2010)4.

Depreende-se que, gradualmente, resultados de desempenho de alunos em testes de larga escala vêm sendo incorporados como indicador relevante de sucesso (ou não) de políticas educacionais e de práticas escolares, o que tende a induzir administradores a colocarem em suas agendas o compromisso com a melhoria do rendimento escolar dos alunos, além de fluxo escolar, tradicionalmente considerado como referência de qualidade. Permite, ainda, supor que a vinculação da gestão a resultados de avaliação, particularmente das avaliações em larga escala, movimento que vem se consolidando e tem sido analisado em estudos da área (SOUSA, 1997; AFONSO, 2000), tende a se fortalecer, ao tempo em que iniciativas de autoavaliação institucional emergem, mesmo que de modo tímido, como apropriação, pela escola, de regulação de seus próprios rumos. Pesquisas nessa direção são oportunas.

\section{Referências}

AFONSO, A. J. Avaliação educacional: regulação e emancipação. São Paulo: Vozes, 2000.

ALVES, Fátima. Políticas educacionais e desempenho escolar nas capitais brasileiras. Cadernos de Pesquisa, São Paulo, v. 38, n. 134, p. 413-440, maio/ago. 2008.

BRANDALISE, M. A. T. Autoavaliação da escola: processo construído coletivamente nas instituições escolares. In: SIMPÓSIO BRASILEIRO DE POLITICA E ADMINISTRAÇÃO DA EDUCAÇÃO, 23., 2007, Porto Alegre; CONGRESSO LUSO-BRASILEIRO DE POLITICA E ADMINISTRAÇÃO DA EDUCAÇÃO, 5., 2007; COLÓOUIO IBERO-AMERICANO DE POLITICA E ADMINISTRAÇÃO DA EDUCAÇÃO, 23., 2007, Porto Alegre. Por uma escola de qualidade para todos: formação, financiamento e gestão da educação: anais... Porto Alegre: Anpae: UFGRS, FACED, PPGEDU, 2007. 1 CD-ROM.

BRANDÃO, Z. Fluxos escolares e efeitos agregados pelas escolas. Em Aberto. Brasilia, DF, v. 17, n. 71, p. 41-48, jan. 2000. 
BRASIL. Lei $n^{\circ}$. 9.394, de 20 de dezembro de 1996. Estabelece as diretrizes e bases da educação nacional. Diário Oficial [da] República Federativa do Brasil, Brasilia, DF, 23 dez. 1996.

BRESSOUX, P. Lês recherches sur lês effets-écoles et lês effets-maitres. Revue Française de Pédagogie, Lyon, n. 108, p. 91-137, juil./sept.1994.

BROOKE, N.; SOARES, J. F. Pesquisa em eficácia escolar: origem e trajetórias. Belo Horizonte : Ed. UFMG, 2008.

COE, R.; FITZ-GIBBON, C. School effectiveness research: criticisms and recommendations. Oxford Review of Education, London, v. 24, n. 4, p. 421-437, 1998.

COELHO, S. M. de A. A avaliação institucional das escolas públicas no Estado do Ceará. Gestão em Ação, Salvador, v. 5, n. 1, p. 29-38, jan./jun. 2002.

DALBEN A. Avaliação institucional participativa na educação básica: possibilidades, limitações e potencialidades. 2008. 243 f. Dissertação (Mestrado) - Universidade Estadual de Campinas, Campinas, SP, 2008. Orientador: Mara Regina Lemes de Sordi.

FONSECA, J. L. S. da. Pesquisas sobre efeito escola: uma contribuição para a qualidade da Educação no Brasil. Revista Contemporânea de Educação, Rio de Janeiro, v. 2, n. 4, p. 1-12, 2007.

FREITAS, D. N. T. de. 0 desaproveitamento escolar como objeto de gestão. Intermeio, Campo Grande, v. 12, n. 23, p. 58-68. 2006.

FREITAS, L. C. de. Qualidade negociada: avaliação e contra-regulação na escola pública. Educação \&t Sociedade, Campinas, SP, v. 26, n. 92, p. 911-933, out. 2005.

GOMES, F. C. O perfil dos diretores da escola fundamental e seus estilos de gestão: um estudo a partir do Saeb 2001. 2004. 149 f. Dissertação (Mestrado)- Pontificia Universidade Católica do Rio de Janeiro, Rio de Janeiro, [Orientador: Alicia Maria Catalano de Bonamino]

GROCHOSKA, M. A.; EYNG, A. M. As contribuições da autoavaliação institucional para a escola de Educação Básica: uma experiência de gestão democrática. In: SIMPÓSIO BRASILEIRO DE POLITICA E ADMINISTRAÇÃOO DA EDUCAÇÃO, 23., 2007, Porto Alegre; CONGRESSO LUSO-BRASILEIRO DE POLITICA E ADMINISTRAÇÃO DA EDUCAÇÃO, 5., 2007; COLÓOUIO IBERO-AMERICANO DE POLITICA E ADMINISTRAÇÃO DA EDUCAÇÃO, 23., 2007, Porto Alegre. Por uma escola de qualidade para todos: formação, financiamento e gestão da educação: anais... Porto Alegre: Anpae: UFGRS, FACED, PPGEDU, 2007. 1 CD-ROM. 
MACHADO, E. Gestão democrática e qualidade escolar: elementos que se entrecruzam. 2003. 198 f. Dissertação (Mestrado) - Universidade Federal de Juiz de Fora. Juiz de Fora, 2003. Orientador: Lucia Helena Gonçalves Teixeira.

MAIA, H. G. Avaliação institucional: um instrumento democrático de participação da comunidade escolar. In: SIMPÓSIO BRASILEIRO DE POLITICA E ADMINISTRAÇÃO DA EDUCAÇÃO, 20., 2001, Salvador. Momentos e movimentos: anais..., Piracicaba: Anpae: Unimep, 2001. 1 CD-ROM.

MARTINS, A. M. (Org.). Estado da Arte: gestão, autonomia da escola pública e órgãos colegiados (2000-2008). Brasilia, DF: Liber Ed., 2010.

MARTINS , A. M.; ZIBAS, D.; BUENO, M. S. S. Educação profissional de nível médio: construção de um novo perfil?: relatório final. São Paulo: FCC: FAPESP. 2007. Mimeografado.

MAZZIEIRO, B. V. SAO: Sistemas de Avaliação On-line em instituições educacionais. Revista Ibero-Americana de Estudos em Educação, Araraquara, v. 1, p. 1-12, 2006.

MORAES, S. R. C. de. Autoavaliação institucional numa escola pública básica da rede estadual de São Paulo. 2008. 191f. Dissertação (Mestrado) - Pontifícia Universidade Católica de Campinas, Campinas, SP, 2008. Orientador: Itamar Mendes da Silva.

MORAES, S. R. C. de; SILVA, I. M. da. Autoavaliação de aperfeiçoamento: melhorando a gestão da instituição escolar. In: SIMPÓSIO BRASILEIRO DE POLITICA E ADMINISTRAÇÃO DA EDUCAÇÃO, 23., 2007, Porto Alegre; CONGRESSO LUSOBRASILEIRO DE POLITICA E ADMINISTRAÇÃO DA EDUCAÇÃO, 5., 2007; COLÓQUIO IBERO-AMERICANO DE POLITICA E ADMINISTRAÇÃO DA EDUCAÇÃO, 23., 2007, Porto Alegre. Por uma escola de qualidade para todos: formação, financiamento e gestão da educação: anais... Porto Alegre: Anpae: UFGRS, FACED, PPGEDU, 2007. 1 CD-ROM.

OLIVEIRA, E. C. S. de. A Avaliação no contexto do projeto político-pedagógico de uma escola: concepção, finalidades e abrangência. 2002. 120 f. Dissertação (Mestrado) Universidade de Brasilia, Brasillia, DF, 2002. Orientador: Benigna Maria de Freitas Villas Boas.

RIBEIRO, M. T. de M. A dificil tarefa de manter uma escola de sucesso. In: REUNIÃO ANUAL DA ANPED, 27., 2004, Caxambu. Anais... Rio de Janeiro: Anped, 2004. 1 CD-ROM.

SILVA, M. L. da. A avaliação institucional das escolas técnicas do Centro Estadual de Educação Tecnológica Paula Souza (1997 - 2007). 2008. 314 f. Tese (Doutorado) - Universidade Federal de São Carlos, São Carlos, SP, 2008. Orientador: Waldemar Marques. 
SOARES, J. F.; ANDRADE, R. J. de. Nivel socioeconômico, qualidade e equidade das escolas de Belo Horizonte. Ensaio: avaliação e políticas públicas em Educação, Rio de Janeiro, v. 14, n. 50, mar. 2006.

SOARES, J. F.; CANDIAN, J. F. 0 efeito da escola básica brasileira: as evidências do PISA e do SAEB. Revista Contemporânea de Educação, Rio de Janeiro, v. 2, n. 4, p. 1-12, 2007.

SOARES, T. M.; TEIXEIRA, L. H G. Efeito do perfil do diretor na gestão escolar sobre a proficiência do aluno. Estudos em Avaliação Educacional, São Paulo, n. 34, p. 155-186, maio/ago. 2006.

SOUSA, S. M. Z. L. Avaliação do rendimento escolar como instrumento de gestão educacional. In: OLIVEIRA, D. A. (Org.). Gestão democrática da educação.

Petrópolis: Vozes, 1997.

SOUZA, A. R. de. Perfil da gestão escolar no Brasil. 2007. 322 f. Tese

(Doutorado) - Pontifícia Universidade Católica de São Paulo, São Paulo, 2007a.

Orientador: José Geraldo Silveira Bueno.

. As relações entre os resultados da avaliação e os modelos de gestão

escolar. Intermeio, Campo Grande, v. 13, n. 25, p. 64-81. 2007 b.

SQUILASSE, M. do C. Avaliação escolar: além da avaliação do rendimento do aluno. 2001. 243 f. Dissertação (Mestrado) - Universidade Federal de São Carlos, São Carlos, SP, 2001. Orientador: Joaquim Gonçalves Barbosa.

VIEIRA, S. L. Gestão, avaliação e sucesso escolar: recortes da trajetória cearense. Estudos Avançados, São Paulo, v. 21, n. 60, p. 45-60, maio/ago. 2007.

Recebido em: 16/05/2011

Aceito para publicação em: 04/11/2011 